\title{
Atuação da equipe de saúde bucal na estratégia saúde da família: análise dos estudos publicados no período 2001-2008
}

\author{
Oral health teamwork in brazilian family healthcare strategy: \\ an analysis of studies published between 2001 and 2008
}

\author{
Fabíola Fernandes Soares ${ }^{1}$ \\ Carla Rosa Vilela de Figueiredo ${ }^{2}$ \\ Neyrlene Cavalcanti Moreira Borges ${ }^{2}$ \\ Rodrigo Aquino Jordão ${ }^{2}$ \\ Maria do Carmo Matias Freire ${ }^{3}$
}

${ }^{1}$ Instituto de Assistência dos Servidores Públicos do Estado de Goiás. Auditoria Odontológica- Regional Anápolis. Avenida São Francisco de Assis 890, Jundiaí. $\quad 75110-810$ Anápolis GO

bimyfriend78@hotmail.com

${ }^{2}$ Secretaria Municipal de

Saúde de Goiânia, Goiás, Brasil.

${ }^{3}$ Faculdade de Odontologia, Universidade Federal de Goiânia, Goiás, Brasil.

\begin{abstract}
The scope of this study was to review publications between 2001 and 2008 on the work of the Oral Health Team (OHT) in Family Health Strategy (FHS) in Brazil, seeking to establish the profile of the publications and studies that can assist in the assessment of the inclusion of oral health in the strategy. The sources were articles published in national and international journals included in the LILACS, MEDLINE and BBO databases, as well as non-indexed journals. Only those articles that addressed an assessment of the role of OHT in FHS were selected $(N=20)$. Studies published throughout the period reveal important information, though the evaluation methodologies used in most of them do not adequately show the impact of OHT actions on the conditions and access to oral health of the population attended. Findings also indicate that the municipalities have not fully performed their oral health obligations in accordance with FHS recommendations. Furthermore, barriers and advances have been identified in the construction process in which the practices of the traditional model still dominate. Key words Oral health, Family health strategy, Health assessment, Dissemination of scientific publications
\end{abstract}

Resumo O objetivo do presente estudo foi revisar as publicações no período de 2001 a 2008 sobre a atuação da Equipe de Saúde Bucal (ESB) na Estratégia Saúde da Família (ESF), buscando conhecer o perfil das publicações e os estudos que possam subsidiar a avaliação da inserção da saúde bucal na estratégia. As fontes de publicação consultadas foram artigos publicados em periódicos nacionais e internacionais incluídos nas bases de dados LILACs, MEDLINE e BBO, além de periódicos não indexados. Foram selecionados apenas os artigos que abordavam algum tipo de avaliação da atuação da ESB na ESF $(N=20)$. Os estudos publicados no período analisado apresentam informações importantes, porém as metodologias de avaliação utilizadas na maioria destes não permitem conhecer o impacto das ações da ESB no acesso e na condição de saúde bucal das populações beneficiadas. Os achados indicam ainda que os municípios não têm realizado suas ações de saúde bucal plenamente da forma preconizada pelo Ministério da Saúde. Além disso, barreiras e avanços têm sido identificados no processo de construção em que ainda predominam as práticas do modelo tradicional.

Palavras-chave Saúde bucal, Estratégia saúde da família, Avaliação em saúde, Publicações de divulgação científica 


\section{Introdução}

Em 1988, a saúde é assegurada a todos como um direito na Constituição do Brasil. Dentro desta proposta está o Sistema Único de Saúde (SUS), com seus princípios fundamentados na integralidade da assistência, equidade, universalidade e controle social das ações em saúde. Num esforço para ampliar a atenção básica, concretizar as diretrizes do SUS e reorganizar a forma de assistência surgiu a proposta da Estratégia Saúde da Família (ESF), tendo a unidade familiar como cerne.

O foco centrado no núcleo familiar se justifica pelo fato de que a família é o âmbito no qual se originam e se reforçam hábitos, crenças e valores. A ESF, inicialmente Programa Saúde da Família (PSF), criado em 1994 pelo Ministério da Saúde, se propõe a ser um projeto dinamizador do SUS ${ }^{1}$. Na época de implantação da ESF, a equipe era minimamente composta por médico, enfermeiro, técnico de enfermagem e agentes comunitários de saúde.

Em estudo realizado pelo Instituto Brasileiro de Geografia e Estatística (IBGE) junto com a Pesquisa Nacional por Amostra de Domicílios (PNAD), em 1998 cerca de 29,6 milhões de brasileiros (19\%) nunca tinham ido ao dentista ${ }^{2}$. A divulgação dos resultados desse estudo na mídia causou grande repercussão na sociedade brasileira e o Ministério da Saúde, como resposta a esta situação, publicou em 29 de dezembro de 2000 a portaria MS n 1.444 , que introduziu oficialmente a saúde bucal na ESF através dos incentivos financeiros para as Equipes de Saúde Bucal (ESB) no programa ${ }^{3}$. No primeiro trimestre de 2001 começaram a serem implantadas as primeiras ESB.

O objetivo da inserção das ESB na ESF, segundo o Ministério da Saúde 4 é ampliar o acesso da população brasileira às ações de promoção, prevenção e recuperação da saúde bucal, melhorar os indicadores de saúde, além de incentivar a reorganização desta área na atenção básica.

Segundo dados do Ministério da Saúde, tem havido aumento substancial no número de equipes de saúde bucal desde a sua implantação, resultando em aumento da cobertura populacional. Em 2008, 17.807 equipes de saúde bucal estavam implantadas em cerca de 5,6 mil municípios gerando uma cobertura populacional de $45,3 \%$ da população brasileira, o que corresponderia a cerca de 85,2 milhões de pessoas ${ }^{5}$. A atual Política Nacional de Saúde Bucal, instituída em 2004, tem como uma das diretrizes a operacionalização da oferta de serviços na atenção básica através da ESF6 .
Tendo em vista todas estas mudanças e diretrizes que trazem consigo a promessa de um SUS mais próximo do seu projeto original, não se pode esquecer que esta implantação requer planejamento apurado, acompanhamento e avaliação, as quais são previstas na Política Nacional de Atenção Bási$\mathrm{ca}^{7}$. Estas ações se constituem como essenciais não só porque permitem saber se o que foi previsto está sendo corretamente realizado, mas também por possibilitarem a introdução de ajustes e correções de rumo em planos que sofrem acidentes de percurso, além de contribuírem para a formulação de planos futuros mais perfeitos ${ }^{8}$.

Igualmente importante para a consolidação desse processo avaliativo é a produção de estudos científicos com sua respectiva publicação e divulgação. Existem na literatura diversos trabalhos abordando a avaliação da ESF. Muitos mostram melhores indicadores na ESF quando comparada ao modelo tradicional, com destaque para redução no índice de mortalidade infantil ${ }^{9,10}$. Após oito anos de implantação das equipes de saúde bucal na ESF é necessário verificar se existem na literatura estudos publicados sobre as ações destas equipes, e se essa atuação vem sendo efetiva, tendo em vista que os resultados podem influenciar práticas profissionais, técnicas e aplicações de recursos.

O objetivo do presente estudo foi revisar os estudos publicados no período de 2001 a 2008 sobre a atuação da equipe de saúde bucal na ESF, buscando conhecer o perfil das publicações e os estudos que possam subsidiar a avaliação da inserção da saúde bucal na estratégia.

\section{Métodos}

Foi realizado um estudo do tipo revisão da literatura, incluindo artigos publicados em periódicos nacionais e internacionais, indexados ou não, no período de 2001 (ano da implantação das ESB) a 2008. A busca dos artigos indexados foi realizada em bases de dados nacionais e internacionais disponíveis em meios eletrônicos: LILACs, MEDLINE e BBO. Os periódicos não indexados foram investigados por meio de busca ativa.

Foram utilizados os seguintes descritores na busca dos artigos indexados: Saúde; Bucal; Saúde da família; Programa saúde da família; PSF; Estratégia saúde da família; ESF; Equipe de Saúde Bucal; ESB; Odontologia; Odontológica; Assistência; Atenção; Dentista.

Foram selecionados apenas os artigos baseados em pesquisas originais cujo objetivo era avaliar a atuação da ESB na ESF. Foram excluídos es- 
tudos descritivos sobre o perfil dos cirurgiões dentistas e da população da área de abrangência da ESF, relatos de experiências, bem como as revisões narrativas de literatura e artigos de opinião. Inicialmente foram encontrados 44 artigos; destes, 20 atendiam aos critérios e foram selecionados.

Após a obtenção do texto completo de todos os artigos foi realizada a sua análise por duas revisoras e as informações relevantes foram sistematizadas em uma tabela. Os seguintes dados foram coletados dos trabalhos selecionados: autor(es), ano e fonte da publicação; nacionalidade e área do periódico; língua de publicação; local de realização do estudo; tempo de implantação da ESB na ESF; variáveis de interesse; objetivo do estudo; tipo de estudo e metodologia; e resultados principais.

\section{Resultados}

Foram encontrados 20 artigos de pesquisas originais que abordavam algum tipo de avaliação (processo e resultados) sobre a atuação da Equipe de Saúde Bucal na ESF, todos na língua portuguesa, em nove periódicos nacionais (Tabela 1). $\mathrm{O}$ ano de publicação variou de 2003 a 2008, sendo que grande parte $(47,0 \%)$ dos artigos foram publicados nos últimos dois anos. Dos vinte periódicos, dezessete eram da área de Saúde Coletiva.

Foram identificadas diversas variáveis de interesse, as quais foram agrupadas em quatro temas: perfil de atuação da equipe de saúde bucal, com enfoque em aspectos administrativos e ações realizadas $(n=13)$ (Tabela 1$)$; oferta, demanda e acesso aos serviços $(n=2)$ (Tabela 2$)$; relações entre os sujeitos ( $\mathrm{n}=3$ ) (Tabela 3$)$; e planejamento, programação e avaliação ( $\mathrm{n}=2)$ (Tabela 4$)$.

Os estudos relatados foram realizados principalmente na Região Nordeste $(\mathrm{n}=14)$, mas também no Sudeste $(n=3)$, Sul $(n=2)$ e Norte $(n=1)$. Um total de 138 municípios foram pesquisados, sendo que a maioria dos estudos foi realizada em um único município $(\mathrm{n}=14)$. O tempo de implantação da ESB na ESF dos municípios incluídos variou de 1 a 6 anos, contudo, em oito artigos não foi relatada esta informação. Alguns artigos aparentemente referem-se a uma mesma pesquisa, apresentando conteúdos fragmentados de acordo com diferentes eixos temáticos ${ }^{11-14}$.

Quanto ao tipo de estudo foram identificados os qualitativos $(n=12)$, quantitativos transversais $(n=10)$ e pesquisa documental $(n=6)$. Em muitos estudos $(n=9 ; 45 \%)$ foram realizados mais de um tipo de delineamento, sendo que em oito deles utilizou-se uma combinação das metodologias quanti e qualitativas. Os instrumentos de coleta de dados foram entrevista, questionário, documentos e observação da prática dos serviços. As fontes documentais citadas em quatro dos seis artigos que utilizaram este método foram documentos diversos dos serviços municipais de saúde e educação, enquanto três incluíram os sistemas de informação em saúde (SIASUS e SIAB).

A maioria dos estudos destaca na descrição de seus resultados e/ou conclusões os aspectos positivos e negativos da inclusão da ESB na ESF até o momento da avaliação, ainda que estas variáveis não tenham sido explicitadas como objeto dos estudos (Tabela 1). Como aspectos positivos destacam-se a maior ênfase às ações de promoção, prevenção e educação; a delimitação da clientela possibilitando melhor acompanhamento; o aumento no número de procedimentos odontológicos; a cobertura populacional de acordo com o mínimo estipulado pelo Ministério da Saúde; propostas de trabalho consistentes em fase de implantação; a recepção favorável e satisfação por parte do usuário; a boa integração do cirurgião dentista $(C D)$ com a equipe e sua capacitação na área de saúde pública; e a existência de relações humanizadoras e vínculo entre trabalhadores e usuários.

Os aspectos negativos, abordados em 16 dos 20 trabalhos analisados, foram mais numerosos do que os positivos e incluíram a falta de atividades de planejamento, programação e avaliação; a grande demanda reprimida e a pouca oferta; a não ampliação do acesso aos serviços de saúde bucal em comparação com áreas não cobertas pela ESF; obstáculos nas relações entre os sujeitos; a maior expectativa voltada às ações curativas e queixas relacionadas à presteza no atendimento e resolubilidade do serviço por parte dos usuários; a não percepção do trabalho da ESB pelos usuários; dificuldades referentes ao encaminhamento dos casos de maior complexidade; ausência de THD na equipe; ações com foco no atendimento clínico e valorização excessiva da técnica e da especialidade; predomínio de práticas preventivas e educativas tradicionais; dificuldades no desempenho das atividades; dificuldades na intersetorialidade e no diagnóstico epidemiológico; e contratos precários, baixos salários, frustrações e condições inadequadas de trabalho para o CD (Tabela 1). 
Tabela 1. Estudos sobre avaliação da atuação da Equipe de Saúde Bucal na Estratégia Saúde da Família publicados no período 2001-2008.

\begin{tabular}{|c|c|c|c|}
\hline $\begin{array}{l}\text { Autor, } \\
\text { ano de publicação } \\
\text { (referência) e fonte }\end{array}$ & $\begin{array}{c}\text { Local de realização } \\
\text { do estudo } \\
\text { (Tempo de implantação } \\
\text { da ESB na ESF) }\end{array}$ & Objetivo geral & $\begin{array}{l}\text { Tipo de estudo e } \\
\text { medodologia }\end{array}$ \\
\hline $\begin{array}{l}\text { Farias e Moura, } \\
2003^{1} \\
\text { Revista de } \\
\text { Odontologia da } \\
\text { Unesp }\end{array}$ & Iracema-CE (1 ano) & $\begin{array}{l}\text { Identificar os benefícios e } \\
\text { obstáculos relacionados à } \\
\text { implementação de ações de } \\
\text { saúde bucal. Análise } \\
\text { comparativa do ano de } \\
\text { implantação (2001) com o } \\
\text { ano de } 1998 \text {. }\end{array}$ & $\begin{array}{l}\text { Análise documental } \\
\text { (Relatório de Gestão, Plano } \\
\text { Municipal de Saúde, } \\
\text { pequenos informes das } \\
\text { Secretarias de Saúde e } \\
\text { Educação do município, e } \\
\text { informações do SIA-SUS e } \\
\text { SIAB) e estudo qualitativo } \\
\text { (observação participante) }\end{array}$ \\
\hline $\begin{array}{l}\text { Baldani et al., } \\
2005^{12} \\
\text { Cadernos de Saúde } \\
\text { Pública }\end{array}$ & $\begin{array}{l}77 \text { municípios do PR } \\
\text { (1 ano })\end{array}$ & $\begin{array}{l}\text { Analisar o perfil de } \\
\text { implantação da odontologia } \\
\text { no Programa Saúde da } \\
\text { Família no Estado do } \\
\text { Paraná. }\end{array}$ & $\begin{array}{l}\text { Quantitativo transversal e } \\
\text { qualitativo (questionário } \\
\text { para o Coordenador de } \\
\text { Saúde Bucal ou Secretário } \\
\text { Municipal de Saúde e CD) }\end{array}$ \\
\hline $\begin{array}{l}\text { Oliveira e Saliba, } \\
2005^{13} \\
\text { Ciência \& Saúde } \\
\text { Coletiva }\end{array}$ & $\begin{array}{l}\text { Campos dos } \\
\text { Goytacazes-RJ } \\
\quad(1 \text { ano })\end{array}$ & $\begin{array}{l}\text { Avaliar a situação da equipe } \\
\text { de saúde bucal }\end{array}$ & $\begin{array}{l}\text { Quantitativo transversal } \\
\text { (entrevista com CD, ACD, } \\
\text { THD, ACS e usuários) }\end{array}$ \\
\hline $\begin{array}{l}\text { Padilha et al., } \\
2005^{14} \\
\text { Pesquisa Brasileira } \\
\text { de Odontopediatria } \\
\text { e Clínica Integrada }\end{array}$ & 12 municípios da $\mathrm{PB}$ & $\begin{array}{l}\text { Descrever as características } \\
\text { do planejamento, } \\
\text { programação e avaliação em } \\
\text { Odontologia na ESF no } \\
\text { Estado da Paraíba }\end{array}$ & $\begin{array}{l}\text { Qualitativo (entrevista com } \\
\text { Secretários Municipais de } \\
\text { Saúde, gerentes e/ou } \\
\text { programadores em saúde } \\
\text { bucal e CD) }\end{array}$ \\
\hline $\begin{array}{l}\text { Rodrigues e Assis, } \\
2005^{15} \\
\text { Revista Baiana de } \\
\text { Saúde Pública }\end{array}$ & Alagoinhas-BA (3 anos) & $\begin{array}{l}\text { Analisar a dinâmica } \\
\text { organizacional da oferta e } \\
\text { demanda dos serviços de } \\
\text { saúde bucal, tomando como } \\
\text { eixo orientador fluxogramas } \\
\text { analisadores do processo de } \\
\text { trabalho em saúde }\end{array}$ & $\begin{array}{l}\text { Qualitativo (entrevista com } \\
\text { a ESB, ACS, equipe de saúde } \\
\text { e informantes-chave), } \\
\text { observação sistemática da } \\
\text { prática e fontes } \\
\text { documentais (Normas e } \\
\text { Rotinas do Setor } \\
\text { Odontológico da Secretaria } \\
\text { Municipal de Saúde) }\end{array}$ \\
\hline $\begin{array}{l}\text { Santos e Assis, } \\
2005^{16} \\
\text { Revista Baiana de } \\
\text { Saúde Pública }\end{array}$ & Alagoinhas-BA (3 anos) & $\begin{array}{l}\text { Compreender as relações } \\
\text { estabelecidas entre os } \\
\text { diferentes sujeitos que } \\
\text { atuam, se responsabilizam } \\
\text { ou se articulam com a } \\
\text { prática de saúde bucal }\end{array}$ & $\begin{array}{l}\text { Qualitativo (entrevista com } \\
\text { a ESB, equipe de saúde, } \\
\text { usuários e informantes- } \\
\text { chave) e observação } \\
\text { sistemática da prática }\end{array}$ \\
\hline $\begin{array}{l}\text { Andrade e Ferreira, } \\
2006^{17} \\
\text { Ciência \& Saúde } \\
\text { Coletiva }\end{array}$ & Pompeu-MG (1 ano) & $\begin{array}{l}\text { Avaliar alguns aspectos da } \\
\text { inclusão da } \\
\text { saúde bucal no PSF pelo } \\
\text { olhar dos usuários }\end{array}$ & $\begin{array}{l}\text { Quali-quantitativo } \\
\text { (entrevista com usuários) }\end{array}$ \\
\hline $\begin{array}{l}\text { Araújo e } \\
\text { Dimenstein, } 2006^{18} \\
\text { Ciência \& Saúde } \\
\text { Coletiva }\end{array}$ & $\begin{array}{l}6 \text { municípios do RN } \\
\text { (3 anos) }\end{array}$ & $\begin{array}{l}\text { Analisar o perfil de atuação } \\
\text { de CD inseridos no PSF de } \\
\text { municípios do Rio Grande } \\
\text { do Norte }\end{array}$ & $\begin{array}{l}\text { Quali-quantitativo } \\
\text { (entrevista com CD) }\end{array}$ \\
\hline
\end{tabular}


Tabela 1. continuação

\begin{tabular}{|c|c|c|c|}
\hline $\begin{array}{l}\text { Autor, } \\
\text { ano de publicação } \\
\text { (referência) e fonte }\end{array}$ & $\begin{array}{c}\text { Local de realização } \\
\text { do estudo } \\
\text { (Tempo de implantação } \\
\text { da ESB na ESF) }\end{array}$ & Objetivo geral & $\begin{array}{l}\text { Tipo de estudo e } \\
\text { medodologia }\end{array}$ \\
\hline $\begin{array}{l}\text { Santos e Assis, } \\
2006^{19} \\
\text { Ciência \& Saúde } \\
\text { Coletiva }\end{array}$ & Alagoinhas-BA (3 anos) & $\begin{array}{l}\text { Analisar os dispositivos que } \\
\text { orientam a atenção integral } \\
\text { à saúde bucal: vínculo, } \\
\text { acolhimento, autonomia, } \\
\text { responsabilização e } \\
\text { resolubilidade }\end{array}$ & $\begin{array}{l}\text { Qualitativo (entrevistas com } \\
\text { a ESB, equipe de saúde, } \\
\text { usuários e informantes- } \\
\text { chave); observação da prática } \\
\text { e pesquisa documental } \\
\text { (fontes não explicitadas) }\end{array}$ \\
\hline $\begin{array}{l}\text { Vilarinho, Mendes } \\
\text { e Prado Júnior, } \\
2007^{20} \\
\text { Revista Odonto } \\
\text { Ciência }\end{array}$ & Iracema-CE & $\begin{array}{l}\text { Analisar o perfil de atuação } \\
\text { dos CD inseridos no PSF, } \\
\text { buscando conhecer e } \\
\text { compreender sua } \\
\text { experiência de trabalho }\end{array}$ & $\begin{array}{l}\text { Quantitativo transversal } \\
\text { (questionário para CD) }\end{array}$ \\
\hline $\begin{array}{l}\text { Facó et al., } 2007^{21} \\
\text { Revista Brasileira } \\
\text { em Promoção da } \\
\text { Saúde }\end{array}$ & 10 municípios do $\mathrm{CE}$ & $\begin{array}{l}\text { Analisar o perfil do CD no } \\
\text { PSF, levando em } \\
\text { consideração o tipo de } \\
\text { trabalho desenvolvido, a } \\
\text { satisfação, a motivação e a } \\
\text { qualificação dos } \\
\text { profissionais }\end{array}$ & $\begin{array}{l}\text { Quantitativo transversal } \\
\text { (entrevista com CD) }\end{array}$ \\
\hline $\begin{array}{l}\text { Souza e Roncalli, } \\
2007^{22} \\
\text { Cadernos de Saúde } \\
\text { Pública }\end{array}$ & $\begin{array}{l}19 \text { municípios do } \mathrm{RN} \\
\text { (no mínimo } 1 \text { ano) }\end{array}$ & $\begin{array}{l}\text { Avaliar a incorporação da } \\
\text { saúde bucal no PSF, com } \\
\text { base na análise de fatores } \\
\text { que interferem positiva ou } \\
\text { negativamente na } \\
\text { implementação dessa } \\
\text { estratégia }\end{array}$ & $\begin{array}{l}\text { Quantitativo transversal } \\
\text { (entrevistas estruturadas } \\
\text { com gestores e CD); } \\
\text { observação estruturada e } \\
\text { pesquisa documental } \\
\text { (relatórios, projetos, fichas } \\
\text { clínicas utilizadas pelo } \\
\text { município e protocolos de } \\
\text { atendimento) }\end{array}$ \\
\hline $\begin{array}{l}\text { Almeida e Ferreira, } \\
2008^{23} \\
\text { Cadernos de Saúde } \\
\text { Pública }\end{array}$ & Natal-RN & $\begin{array}{l}\text { Conhecer as práticas } \\
\text { preventivas e educativas em } \\
\text { saúde bucal realizadas pelos } \\
\text { CD }\end{array}$ & $\begin{array}{l}\text { Quantitativo transversal } \\
\text { (entrevista estruturada com } \\
\text { os CD) e pesquisa } \\
\text { documental (SIA-SUS e } \\
\text { SIAB) }\end{array}$ \\
\hline $\begin{array}{l}\text { Emmi e Barroso, } \\
2008^{24} \\
\text { Ciência \& Saúde } \\
\text { Coletiva }\end{array}$ & $\begin{array}{c}\text { Distrito de } \\
\text { Mosqueiro-PA (2 anos) }\end{array}$ & $\begin{array}{l}\text { Avaliar as ações de saúde } \\
\text { bucal executadas }\end{array}$ & $\begin{array}{l}\text { Quantitativo transversal } \\
\text { (questionários para usuários) }\end{array}$ \\
\hline $\begin{array}{l}\text { Rocha e Góes, } \\
2008^{25} \\
\text { Cadernos de Saúde } \\
\text { Pública }\end{array}$ & $\begin{array}{l}\text { Campina Grande-PB } \\
\text { (no mínimo } 2 \text { anos) }\end{array}$ & $\begin{array}{l}\text { Identificar os fatores que } \\
\text { interferem no acesso dos } \\
\text { serviços de saúde bucal, } \\
\text { comparando as áreas } \\
\text { cobertas com as não } \\
\text { cobertas pela ESF }\end{array}$ & $\begin{array}{l}\text { Quantitativo transversal } \\
\text { (questionários para usuários) }\end{array}$ \\
\hline $\begin{array}{l}\text { Santos et al., } 2008^{26} \\
\text { Revista de Saúde } \\
\text { Pública }\end{array}$ & Alagoinhas-BA & $\begin{array}{l}\text { Compreender o } \\
\text { estabelecimento do vínculo } \\
\text { na construção de autonomia } \\
\text { dos sujeitos que engendram } \\
\text { as práticas de saúde bucal no } \\
\text { PSF }\end{array}$ & $\begin{array}{l}\text { Qualitativo (entrevistas } \\
\text { semi-estruturadas com a } \\
\text { ESB, equipe de saúde e } \\
\text { usuários) }\end{array}$ \\
\hline
\end{tabular}


Tabela 1. continuação

\begin{tabular}{|c|c|c|c|}
\hline $\begin{array}{l}\text { Autor, } \\
\text { ano de publicação } \\
\text { (referência) e fonte }\end{array}$ & $\begin{array}{c}\text { Local de realização } \\
\text { do estudo } \\
\text { (Tempo de implantação } \\
\text { da ESB na ESF) }\end{array}$ & Objetivo geral & $\begin{array}{l}\text { Tipo de estudo e } \\
\text { medodologia }\end{array}$ \\
\hline $\begin{array}{l}\text { Koyashiki et al., } \\
2008^{27} \\
\text { Ciêcia \& Saúde } \\
\text { Coletiva }\end{array}$ & Londrina-PR & $\begin{array}{l}\text { Compreender otrabalho em } \\
\text { saúde bucal do ACS em } \\
\text { Unidades de Saúde da } \\
\text { Família }\end{array}$ & $\begin{array}{l}\text { Qualitativo (entrevista com } \\
\text { ACS e análise do discurso) }\end{array}$ \\
\hline $\begin{array}{l}\text { Pimentel et al., } \\
2008^{28} \\
\text { Revista Baiana de } \\
\text { Saúde Pública }\end{array}$ & Recife-PE (6 anos) & $\begin{array}{l}\text { Analisar a evolução das } \\
\text { ações realizadas pelas } \\
\text { equipes desaúde bucal no } \\
\text { município do Recife no } \\
\text { período de } 2001 \text { a } 2007 \text {, } \\
\text { utilizando-se o SIASUS }\end{array}$ & $\begin{array}{l}\text { Pesquisa documental } \\
\text { (SIA-SUS) }\end{array}$ \\
\hline $\begin{array}{l}\text { Terreri e Soler, } \\
2008^{29} \\
\text { Cadernos de Saúde } \\
\text { Pública }\end{array}$ & Ipiguá-SP & $\begin{array}{l}\text { Avaliar dois critérios } \\
\text { utilizados no PSF para } \\
\text { determinação da prioridade } \\
\text { do atendimento } \\
\text { odontológico curativo da } \\
\text { cárie }\end{array}$ & Quantitativo transversal \\
\hline $\begin{array}{l}\text { Chaves e Miranda, } \\
2008^{30} \\
\text { Interface - } \\
\text { Comunicação, } \\
\text { Saúde, Educação }\end{array}$ & 4 municípios do $\mathrm{CE}$ & $\begin{array}{l}\text { Conhecer as percepções } \\
\text { sobre a própria inserção e } \\
\text { atuação }\end{array}$ & $\begin{array}{l}\text { Qualitativo (entrevista com } \\
\text { CD e análise de conteúdo) }\end{array}$ \\
\hline
\end{tabular}

$\mathrm{ACD}=$ Auxiliar de Consultório Dentário; $\mathrm{ACS}=$ Agente Comunitário de Saúde; $\mathrm{CD}=$ Cirurgião Dentista; ESB= Equipe de Saúde Bucal; MS= Ministério da Saúde; PSF= Programa Saúde da Família; SIAB= Sistema de Informação de Atenção Básica; SIA-SUS= Sistema de Informações Ambulatoriais do SUS; THD= Técnico em Higiene Dental.

\section{Discussão}

Os resultados desta revisão mostram que há na literatura um crescente interesse pelo tema, manifestado pelo aumento no número de artigos publicados nos últimos anos. O fato de não terem sido encontrados mais estudos sobre avaliação da atuação ESB na ESF, não quer dizer que não existam. Neste estudo foram levantados apenas os que foram publicados e pode ser que os municípios estejam realizando pesquisas avaliativas rotineiras ou eventuais, sem interesse em publicação. O predomínio dos municípios do Nordeste é compatível com o maior número de equipes de saúde da família naquela Região em relação às demais, 48,8\% das ESB do país encontravam-se nessa região até o ano de $2008^{5}$. O presente estudo, portanto, não tem intenção de ter esgotado o referido tema, apenas descreve os achados dentro da metodologia aqui proposta.
Em um levantamento mais amplo da produção bibliográfica sobre a ESB na ESF no período 2001-2007, que incluiu resumos de trabalhos apresentados em eventos científicos e de dissertações e teses, além dos artigos publicados, foram observados inúmeros resumos em anais e proporcionalmente poucos trabalhos completos publicados em periódicos ${ }^{31}$. A maioria dos trabalhos, publicados ou não, eram relatos de experiência ou estudos descritivos sobre outros temas que incluíam em sua amostra grupos populacionais da área de abrangência da ESF. Além disso, poucos eram do tipo pesquisa avaliativa sobre a inserção da ESB na ESF. A baixa taxa de publicação de artigos de trabalhos da área de odontologia apresentados na forma de resumos em um evento $(15 \%)$ foi relatada também por Leles et al. ${ }^{32}$, que sugeriram a necessidade de medidas para a redução das barreiras à publicação de artigos e maiores incentivos no processo de publicação ${ }^{32}$. 
Tabela 2. Estudos sobre oferta, demanda e acesso aos serviços da Equipe de Saúde Bucal na Estratégia Saúde da Família publicados no período 2001-2008.

\begin{tabular}{|c|c|c|c|}
\hline $\begin{array}{l}\text { Autor, } \\
\text { ano de publicação } \\
\text { (referência) e fonte }\end{array}$ & $\begin{array}{c}\text { Local de realização } \\
\text { do estudo } \\
\text { (Tempo de implantação } \\
\text { da ESB na ESF) }\end{array}$ & Objetivo geral & $\begin{array}{l}\text { Tipo de estudo e } \\
\text { metodologia }\end{array}$ \\
\hline $\begin{array}{l}\text { Rodrigues e Assis, } \\
2005^{15} \\
\text { Revista Baiana de } \\
\text { Saúde Pública }\end{array}$ & Alagoinhas-BA ( 3 anos) & $\begin{array}{l}\text { Analisar a dinâmica } \\
\text { organizacional da oferta e } \\
\text { demanda dos serviços de } \\
\text { saúde bucal, tomando como } \\
\text { eixo orientador fluxogramas } \\
\text { analisadores do processo de } \\
\text { trabalho em saúde }\end{array}$ & $\begin{array}{l}\text { Qualitativo (entrevista com } \\
\text { a ESB, ACS, equipe de } \\
\text { saúde e informantes- } \\
\text { chave), observação } \\
\text { sistemática da prática e } \\
\text { fontes documentais } \\
\text { (Normas e Rotinas do } \\
\text { Setor Odontológico da } \\
\text { Secretaria Municipal de } \\
\text { Saúde) }\end{array}$ \\
\hline $\begin{array}{l}\text { Rocha e Góes, } 2008^{25} \\
\text { Cadernos de Saúde } \\
\text { Pública }\end{array}$ & $\begin{array}{l}\text { Campina Grande-PB } \\
\text { (no mínimo } 2 \text { anos) }\end{array}$ & $\begin{array}{l}\text { Identificar os fatores que } \\
\text { interferem no acesso dos } \\
\text { serviços de saúde bucal, } \\
\text { comparando as áreas cobertas } \\
\text { e não cobertas pela ESF }\end{array}$ & $\begin{array}{l}\text { Quantitativo transversal } \\
\text { (questionários para } \\
\text { usuários) }\end{array}$ \\
\hline
\end{tabular}

ACS= Agente Comunitário de Saúde; ESB= Equipe de Saúde Bucal; ESF= Estratégia Saúde da Família.

Tabela 3. Estudos sobre as relações entre os sujeitos da Equipe de Saúde Bucal na Estratégia Saúde da Família, publicados no período 2001-2008.

\begin{tabular}{|c|c|c|c|}
\hline $\begin{array}{l}\text { Autor, } \\
\text { ano de publicação } \\
\text { (referência) e fonte }\end{array}$ & $\begin{array}{c}\text { Local de realização } \\
\text { do estudo } \\
\text { (Tempo de implantação } \\
\text { da ESB na ESF) }\end{array}$ & Objetivo geral & $\begin{array}{l}\text { Tipo de estudo e } \\
\text { metodologia }\end{array}$ \\
\hline $\begin{array}{l}\text { Santos e Assis, } \\
2005^{16} \\
\text { Revista Baiana de } \\
\text { Saúde Pública }\end{array}$ & Alagoinhas-BA (3 anos) & $\begin{array}{l}\text { Compreender as relações } \\
\text { estabelecidas entre os } \\
\text { diferentes sujeitos que } \\
\text { atuam, se responsabilizam } \\
\text { ou se articulam com a } \\
\text { prática de saúde bucal }\end{array}$ & $\begin{array}{l}\text { Qualitativo (entrevista com } \\
\text { a ESB, equipe de saúde, } \\
\text { usuários e informantes- } \\
\text { chave) e observação } \\
\text { sistemática da prática }\end{array}$ \\
\hline $\begin{array}{l}\text { Santos e Assis, } \\
2006^{19} \\
\text { Ciência \& Saúde } \\
\text { Coletiva }\end{array}$ & Alagoinhas-BA (3 anos) & $\begin{array}{l}\text { Analisar os dispositivos que } \\
\text { orientam a atenção integral } \\
\text { à saúde bucal: vínculo, } \\
\text { acolhimento, autonomia, } \\
\text { responsabilização e } \\
\text { resolubilidade }\end{array}$ & $\begin{array}{l}\text { Qualitativo (entrevistas } \\
\text { com a ESB, equipe de } \\
\text { saúde, usuários e } \\
\text { informantes-chave); } \\
\text { observação da prática e } \\
\text { pesquisa documental } \\
\text { (fontes não explicitadas) }\end{array}$ \\
\hline $\begin{array}{l}\text { Santos et al., } 2008^{26} \\
\text { Revista de Saúde } \\
\text { Pública }\end{array}$ & Alagoinhas-BA & $\begin{array}{l}\text { Compreender o } \\
\text { estabelecimento do vínculo } \\
\text { na construção de autonomia } \\
\text { dos sujeitos que engendram } \\
\text { as práticas de saúde bucal no } \\
\text { PSF }\end{array}$ & $\begin{array}{l}\text { Qualitativo (entrevistas } \\
\text { semi-estruturadas com a } \\
\text { ESB, equipe de saúde e } \\
\text { usuários) }\end{array}$ \\
\hline
\end{tabular}

ESB= Equipe de Saúde Bucal; ESF= estratégia Saúde da Família; PSF= Programa Saúde da Família. 
Tabela 4. Estudos sobre planejamento, programação e avaliação da Equipe de Saúde Bucal na Estratégia Saúde da Família, publicados no período 2001-2008

\begin{tabular}{|c|c|c|c|}
\hline $\begin{array}{l}\text { Autor, } \\
\text { ano de publicação } \\
\text { (referência) e fonte }\end{array}$ & $\begin{array}{c}\text { Local de realização } \\
\text { do estudo } \\
\text { (Tempo de implantação } \\
\text { da ESB na ESF) }\end{array}$ & Objetivo geral & $\begin{array}{l}\text { Tipo de estudo e } \\
\text { metodologia }\end{array}$ \\
\hline $\begin{array}{l}\text { Padilha et al., } 2005^{14} \\
\text { Pesquisa Brasileira de } \\
\text { Odontopediatria e } \\
\text { Clínica Integrada }\end{array}$ & 12 municípios da $\mathrm{PB}$ & $\begin{array}{l}\text { Descrever as características } \\
\text { do planejamento, } \\
\text { programação e avaliação em } \\
\text { Odontologia na ESF no } \\
\text { Estado da Paraíba }\end{array}$ & $\begin{array}{l}\text { Qualitativo (entrevista com } \\
\text { Secretários Municipais de } \\
\text { Saúde, gerentes e/ou } \\
\text { programadores em saúde } \\
\text { bucal e CD) }\end{array}$ \\
\hline $\begin{array}{l}\text { Terreri e Soler, } 2008^{29} \\
\text { Cadernos de Saúde } \\
\text { Pública }\end{array}$ & Ipiguá-SP & $\begin{array}{l}\text { Avaliar dois critérios } \\
\text { utilizados no PSF para } \\
\text { determinação da prioridade } \\
\text { do atendimento } \\
\text { odontológico curativo da } \\
\text { cárie }\end{array}$ & Quantitativo transversal \\
\hline
\end{tabular}

CD= Cirurgião Dentista; ESB= Equipe de Saúde Bucal; ESF= Estratégia Saúde da Família; PSF= Programa Saúde da Família.

Dois aspectos chamam a atenção no presente estudo. O primeiro é o fato de que somente um dos estudos realizou comparação da ESF com o modelo convencional de atenção ${ }^{25}$. Nos demais foi realizada apenas a análise descritiva das questões inerentes à ESB na ESF. Outro aspecto é o predomínio de dados referentes à percepção dos sujeitos que participam da ESF, incluindo gestores, trabalhadores e usuários, por meio de entrevistas e questionários. Apesar da grande contribuição que esta metodologia pode oferecer à pesquisa científica, a não inclusão de indicadores objetivos a partir dos documentos e sistemas de informação existentes pode não revelar aspectos importantes e concretos da prática do serviço. A alta proporção de estudos qualitativos representa, por outro lado, a possibilidade de traduzir melhor os olhares dos sujeitos envolvidos, as questões subjetivas envolvidas, acrescentando uma dimensão importante à avaliação das ações na área da saúde ${ }^{33}$. A combinação de métodos quanti e qualitativos representa, portanto, uma boa estratégia de pesquisa.

Para Souza e Roncalli22 as avaliações das ações são realizadas principalmente pelos gestores, o que não seria problemático se a gerência compartilhasse suas análises, resultados e possibilidades de mudanças com os profissionais que trabalham na ponta do serviço. Em seu estudo realizado em municípios do Rio Grande do Norte, apontaram ainda que a fragilidade e a precariedade das fontes utilizadas para avaliação, a ine- xistência de documentos importantes como protocolos, relatórios e a limitação de indicadores de saúde bucal no Sistema de Informação da Atenção Básica (SIAB), tanto para gestores como para dentistas, tornava a situação ainda mais crítica. Conclusões semelhantes foram relatadas por Cericato et al. ${ }^{33}$ em sua revisão de seis estudos sobre as ações e os métodos de avaliação realizados no âmbito da odontologia dentro da ESF.

Não há parâmetros nacionais de avaliação da saúde bucal na ESF e não foram encontrados estudos de base nacional ou macro regional nas publicações analisadas. Contudo, algumas iniciativas do Ministério da Saúde têm proposto diretrizes para o desenvolvimento de ações de avaliação da estratégia.

Uma dessas iniciativas é Projeto de Extensão e Consolidação da Saúde da Família (PROESF), criado em 2003, que pressupõe três componentes, sendo o terceiro de monitoramento e avaliação. A operacionalização desse componente tem como proposição seguir processos seletivos e contar com a cooperação técnica de instituições de ensino e pesquisa para realização de ações de avaliação das equipes e desempenho dos serviços ${ }^{34}$.

$\mathrm{Na}$ literatura, dos três estudos do tipo Estudos de Linha de Base (ELB) do PROESF, apenas um aborda saúde bucal. Nele Szwarcwald et al. ${ }^{35}$ observaram que em quatro municípios com mais de 100 mil habitantes, no Rio de Janeiro, em 2005, menos de $30 \%$ dos domicílios era cadastrado e nesses a assistência bucal era precária. A propor- 
ção de pessoas que realizaram consulta odontológica para revisão periódica pelo menos uma vez ao ano não alcançou 50\% em nenhuma localidade.

Outra iniciativa ministerial é a Avaliação para Melhoria da Qualidade (AMQ), metodologia de autogestão dos processos de melhoria contínua da qualidade desenvolvida especificamente para a ESF tem como um dos eixos centrais a avaliação como instrumento de gestão ${ }^{36}$. Trata de uma auto-avaliação embasada no tripé estabelecido por Donabedian ${ }^{37}$, de estrutura, processo e de resultado em busca do estágio de qualidade (do elementar ao avançado) em que se encontra uma determinada ESF. Está dirigido ao âmbito municipal e oferece instrumentos para avaliação - planejamento - gestão da estratégia. Por ser um processo auto-avaliativo a adesão é facultativa pelos gestores municipais, não há incentivos (premiações) ou sanções (punições) financeiras, ou outras relacionadas aos resultados ${ }^{36}$.

Os estudos incluídos na presente análise apresentam como variáveis de interesse diversos aspectos relacionados à atuação da ESB na ESF. Porém, somente um teve como objetivo avaliar se houve a esperada ampliação do acesso da população aos serviços de saúde bucal comparando-se áreas com e sem cobertura da ESF a partir de questionários com usuários, e os resultados não evidenciaram maior acesso nas áreas beneficiadas pela $\mathrm{ESF}^{17}$. Além disso, o relato do acesso pelo excesso de demanda, por meio de filas, sem territorialização, nem mapeamento ${ }^{12,17,22}$ é contraditório à proposta ministerial ${ }^{38}$. De acordo com os Cadernos de Atenção Básica no 17, que abordam a reorganização das ações e serviços de saúde bucal no âmbito da atenção básica ${ }^{38}$, a agenda deve estar pautada nas necessidades da população a partir de critérios epidemiológicos das áreas de abrangência e/ou de influência das unidades de saúde de forma equânime e universal, devendo ser amplamente discutida com a comunidade, nos conselhos de saúde em nível local e municipal. Não havendo programação, nem articulação comunitária, os resultados desses estudos apontam para a necessidade, em princípio, de reorientação de rotinas instituídas, porém indesejáveis, destacando, assim, o agendamento das consultas e atendimento das urgências.

Outro aspecto fundamental a ser avaliado é se tem havido melhora na condição de saúde bucal da população com a inclusão da ESB na ESF, que poderia ser um indicador de efetividade da estratégia. Apesar dos relatos de satisfação dos usuários em relação a esta questão em um dos municípios pesquisados ${ }^{24}$, nenhum outro es- tudo a investigou por meio de indicadores clínicos epidemiológicos. Uma provável razão pode ser o curto período de atuação das ESB nos municípios pesquisados, insuficiente para produzir impactos perceptíveis na condição de saúde bucal das populações. No estudo realizado em Teresina- $\mathrm{PI}^{20}$, o conhecimento dos CD sobre a condição de saúde bucal da população foi investigado e a maioria dos CD $(87,6 \%)$ afirmaram não conhecer o índice CPOD da área de atuação. Estes achados são preocupantes, tendo em vista que, segundo as Diretrizes da Política Nacional de Saúde $\mathrm{Bucal}^{39}$, Para melhor identificar os principais grupos de ações de promoção, de proteção e de recuperação da saúde a serem desenvolvidas prioritariamente, é necessário conhecer as características do perfil epidemiológico da população, não só em termos de doenças de maior prevalência, como das condições sócio-econômicas da comunidade, seus hábitos e estilos de vida e suas necessidades de saúde -sentidas ou não-, aí incluídas por extensão a infra-estrutura de serviços disponíveis.

Em geral, os estudos analisados mostram que, na grande maioria dos municípios pesquisados, as ações da ESB na ESF não têm sido realizadas de forma satisfatória tendo como parâmetro as diretrizes constantes nos documentos oficiais. Predominam as características do modelo tradicional de atenção, indicando que o incentivo financeiro parece não ser suficiente para promover as mudanças desejadas.

Cardoso et al..$^{40}$ pontuam que para cumprir as atribuições, tais como foram propostas pelos documentos, todas as equipes de saúde deveriam passar por processo de capacitação, a fim de legitimar a saúde bucal como um dos componentes da saúde em sua expressão mais ampla: a da qualidade de vida. A necessidade de melhorar a formação dos profissionais é preocupação de muitos autores ${ }^{21,41-43}$, para definitivamente representar perfil e prática profissional consoantes com os fundamentos da ESF ${ }^{18,21,43}$. Matos e Tomita $^{42}$ verificaram a concepção dos formadores (diretores e coordenadores pedagógicos) e estudantes de odontologia (quarto ano da graduação) sobre a atuação do cirurgião dentista na ESF. Observaram que tanto formadores quanto estudantes apresentam conceitos em construção sobre a atuação do cirurgião-dentista na saúde coletiva, sendo necessário maior envolvimento do ensino superior com serviços públicos de saúde, de modo a complementar algumas lacunas na formação e na prática dos CD na ESF.

Para Esposti et al. $^{43}$ há necessidade de mudanças não apenas nos currículos, mas também 
no que se refere à interação teoria-prática. Um importante passo nesta direção é a implantação projeto Ver SUS, que se orienta pela abertura dos órgãos de gestão do SUS como espaços de ensino e aprendizagem ${ }^{44}$. Anacleto e Cutolo ${ }^{45}$ apontaram o Programa Nacional de Reorientação da Formação Profissional em Saúde (Pró-Saúde) como uma saída para solucionar a dificuldade de inversão do modelo assistencial e auxiliar na formação do profissional capaz de trabalhar tanto na prevenção e recuperação quanto na promoção e proteção à saúde.

O panorama da evidência científica disponível até o momento apresenta informações importantes, porém não suficientes para se avaliar o processo e os resultados da inserção da ESB na ESF. Indica que estudos mais amplos, de maior abrangência geográfica, utilizando metodologias avaliativas apropriadas e com foco nos objetivos da inserção da ESB na ESF, são necessários. Outro aspecto a ser considerado são as barreiras à consoli- dação da Estratégia, que podem ser inerentes ao modelo mais amplo e dominante de atenção da área da saúde, bem como aos aspectos políticos, econômicos e educacionais do país, e não apenas os esforços das equipes e dos serviços.

\section{Conclusões}

Conclui-se pelo presente estudo, que as metodologias de avaliação utilizadas na maioria dos estudos não permitem conhecer o impacto das ações da ESB no acesso e na condição de saúde bucal das populações beneficiadas. Os dados indicam ainda que, em geral, os municípios não têm realizado suas ações de saúde bucal plenamente da forma preconizada pelo Ministério da Saúde. Além disso, barreiras e avanços têm sido identificados no processo de construção em que ainda predominam as práticas do modelo tradicional.

\section{Colaboradores}

FF Soares trabalhou na pesquisa, na metodologia, na concepção e redação final. CRV Figueiredo, NCM Borges e RA Jordão trabalharam na pesquisa e na metodologia. MCM Freire orientou o trabalho e trabalhou na metodologia e redação final. 


\section{Referências}

1. Brasil. Ministério da Saúde. Atenção Básica e a Saúde da Família [acessado 2007 set 20]. Disponível em: http://dtr2004.saude.gov.br/dab/atencaobasica.php

2. Barros AJD, Bertoldi AD. Desigualdades na utilização e no acesso a serviços odontológicos: uma avaliação em nível nacional. Cien Saude Colet 2002; 7(4):709-717.

3. Brasil. Portaria ${ }^{\circ} 1444$, de 18 de dezembro de 2000. Estabelece incentivo financeiro para a reorganização da atenção à saúde bucal prestada nos municípios por meio do Programa de Saúde da Família. Diário Oficial da União 2000; 29 dez.

4. Brasil. Ministério da Saúde. Compreendendo melhor a Saúde Bucal na proposta Avaliação para Melhoria da Qualidade - Qualificação da Estratégia Saúde da Família [acessado 2007 set 28]. Disponível em: http:/ /dtr2002. saude.gov.br/proesf/AutoAvaliacaoESF/ Home/pdf/Anexo_saude_bucal_site_2.pdf

5. Brasil. Ministério da Saúde. Atenção Básica e a Saúde da Família [acessado 2009 jan 18]. Disponível em: http://dtr2004.saude.gov.br/dab/docs/abnumeros/ resumo_por_uf_12_2008.pdf

6. Brasil. Ministério da Saúde. Brasil Sorridente [acessado 2009 jan 18]. Disponível em: http://portal. saude.gov.br/portal/saude/visualizar_texto.cfm? idtxt $=21125$ \&janela $=1$

7. Brasil. Ministério da Saúde. Política Nacional de Atenção Básica. 4a ed. Brasília: Ministério da Saúde; 2007.

8. Pinto VG. Planejamento. In: Pinto, VG. Saúde Bucal Coletiva. São Paulo: Editora Santos; 2000. p. 24.

9. Macinko J, Guanais FC, Souza MF. Evaluation of the impact of the family health program on infant mortality in Brazil, 1990-2002. J Epidemiol Community Health 2005; 60:13-19.

10. Macinko J, Marinho de Souza Mde F, Guanais FC, da Silva Simões CC. Going to scale with community-based primary care: An analysis of the family health program and infant mortality in Brazil, 19992004. Soc Science Medicine 2007; 65:2070-2080.

11. Farias MV, Moura ERF. Saúde bucal no contexto do Programa Saúde da Família do município de Iracema, Ceará. Rev Odontol UNESP 2003; 32(2):131-137.

12. Baldani HB, Fadel CB, Possamai T, Queiroz MGS. A inclusão da odontologia no Programa Saúde da Família no estado do Paraná, Brasil. Cad Saude Publica 2005; 21(4):1026-1035.

13. Oliveira JLC, Saliba NA. Atenção odontológica no programa saúde da família de Goytacazes. Cien Saude Colet 2005; 10(Supl.):297-302.

14. Padilha WWN, Valença AMG, Cavalcanti AL, Gomes LB, Almeida RVD, Taveira GS. Planejamento e programação odontológicos no Programa Saúde da Família do Estado da Paraíba: estudo qualitativo. Pesqui Bras Odontopediatria Clín Integr 2005; 5(1):65-75.

15. Rodrigues AAAO, Assis MMA. Oferta e demanda na atenção à saúde bucal: o processo de trabalho no Programa Saúde da Família em Alagoinhas-BA. Rev Baiana Saúde Pública 2005; 29(2):273-285.
16. Santos AM, Assis MMA. Rede de relações dos protagonistas da prática de saúde bucal no Programa Saúde da Família (PSF) de Alagoinhas-BA. Rev Baiana Saúde Pública 2005; 29(2):313-325.

17. Andrade KLC, Ferreira EF. Avaliação da inserção da odontologia no Programa Saúde da Família de Pompéu (MG): a satisfação do usuário. Cien Saude Colet 2006; 11(1):123-130.

18. Araújo YP, Dimenstein M. Estrutura e organização do trabalho do cirurgião-dentista no PSF de municípios do Rio Grande do Norte. Cien Saude Colet 2006; 11(1):219-227.

19. Santos AM, Assis MMA. Da fragmentação à integralidade: construindo e (des)construindo a prática de saúde bucal no Programa de Saúde da Família (PSF) de Alagoinhas, BA. Cien Saude Colet 2006; 11(1):53-61.

20. Vilarinho SMM, Mendes RF, Prado Júnior, R. R. Perfil dos cirurgiões-dentistas integrantes do programa saúde da família em Teresina (PI). Rev Odonto Ciência 2007; 22(55):48-54.

21. Facó EF, Viana LMO, Bastos VA, Nuto SAS. O cirurgião-dentista e o Programa Saúde da Família na microrregião II, Ceará, Brasil. RBPS 2005; 18(2):70-77.

22. Souza TMS, Roncalli AG. Saúde bucal no Programa Saúde da Família: uma avaliação do modelo assistencial. Cad Saude Publica 2007; 23(11):2727-2739.

23. Almeida GCM, Ferreira MAF. Saúde bucal no contexto do Programa Saúde da Família: práticas de prevenção orientadas ao indivíduo e ao coletivo. Cad Saude Publica 2008; 24(9):2131-2140.

24. Emmi DT, Barroso RFF. Avaliação das ações de saúde bucal no Programa Saúde da Família no distrito de Mosqueiro, Pará. Cien Saude Colet 2008; 13(1):35-41.

25. Rocha RACP, Góes PSA. Comparação do acesso aos serviços de saúde bucal em áreas cobertas e não cobertas pela Estratégia Saúde da Família em Campina Grande, Paraíba, Brasil. Cad Saude Publica $2008 ; 24(12): 2871-2880$

26. Santos AM, Assis MMA, Nascimento MAA, Jorge MSB. Vínculo e autonomia na prática de saúde bucal no Programa Saúde da Família. Rev Saude Publica 2008; 42(3):464-470.

27. Koyashiki GAK, Alves-Souza RA, Garanhani ML. O trabalho em saúde bucal do Agente Comunitário de Saúde em Unidades de Saúde da Família. Cien Saude Colet 2008; 13(4):1343-1354.

28. Pimentel FC, Martelli PJL, Araújo Junior JLAC, Lima AS, Santana VGD, Macedo CLSV. Evolução da assistência em saúde bucal na estratégia de saúde da família do município do Recife (PE) no período de 2001 a 2007. Rev Baiana Saúde Pública 2008; 32(2):253-264.

29. Terreri ALM, Soler ZASG. Estudo comparativo de dois critérios utilizados no Programa Saúde da Família na priorização do tratamento da cárie entre crianças de 5 a 12 anos. Cad Sau•de Publica 2008; 24(7):1581-1587. 
30. Chaves MC, Miranda AS. Discursos de cirurgiõesdentistas do Programa Saúde da Família: crise e mudança de habitus na Saúde Pública. Interface Comun Saude Educ 2008; 12(24):153-167.

31. Figueiredo CRV, Soares FF, Borges NCM, Jordão RA. Levantamento da publicação sobre a saúde bucal na Estratégia Saúde da Família [monografia]. Goiânia (GO): Universidade Federal de Goiás; 2007.

32. Leles CR, Rocha SS, Simões PA, Compagnoni MA. Taxa de publicação, na forma de artigos completos, de resumos apresentados em evento científico de pesquisa odontológica. Rev Odontol UNESP 2006; 35(3):141-147.

33. Cericato GO, Garbin D, Fernandes APS. A inserção do cirurgião-dentista no PSF: uma revisão crítica sobre as ações e os métodos de avaliação das Equipes de Saúde Bucal. RFO UPF 2007; 12(3):18-23.

34. Ministério da Saúde. Projeto de extensão e consolidação do saúde da família [acessado 2007 set 20]. Disponível em: http://bvsms.saude.gov.br/bvs/publicacoes/ PROESF.pdf

35. Szwarcwald CL, Mendonça MHM, Andrade CLT. Indicadores de atenção básica em quatro municípios do Estado do Rio de Janeiro, 2005: resultados de inquérito domiciliar de base populacional. Cien Saude Colet 2006; 11(3):643-655.

36. Brasil. Ministério da Saúde. Avaliação para melhoria da qualidade na estratégia saúde da família [acessado 2007 set 20]. Disponível em: http://portal.saude. gov.br/portal/arquivos/pdf/apresentacao_4_roda_ 2007.pdf

37. Donabedian A. The Definition of Quality and Approaches to its Assessment. Explorations in Quality Assessment and Monitoring. Ann Arbor: Health Administration Press; 1980.

38. Brasil. Ministério da Saúde. Saúde bucal, Cadernos da Atenção Básica, no 17. Brasília: Ministério da Saúde; 2006.
39. Ministério da Saúde. Diretrizes da Política Nacional de Saúde Bucal. Brasília: Ministério da Saúde; 2004.

40. Cardoso ACC, Santos Júnior RQ, Souza LEP, Barbosa MBCB. Inserção da equipe de saúde bucal no PSF: um desafio para melhoria da qualidade de atenção à saúde. Rev Baiana Saúde Pública 2002; 26(1/2): 94-98.

41. Volschan BCG, Soares EL, Corvino M. Perfil do profissional de Saúde da Família. Rev Bras Odontol 2002; 59(5):314-316.

42. Matos PES, Tomita NE. A inserção da saúde bucal no Programa Saúde da Família: da universalidade aos pólos de capacitação. Cad Saude Publica 2004; 20(6):1538-1544.

43. Esposti CDD, Oliveira AE, Silva MZ, Lima RCD. Perspectivas da saúde bucal na Estratégia Saúde da Família: dificuldades e avanços. UFES Rev Odontol 2006; 8(3):49-54.

44. Brasil. Ministério da Saúde. Projeto Ver SUS Brasil, vivência e estágio na realidade do sistema único de saúde no Brasil. Brasília: Ministério da Saúde; 2003.

45. Anacleto KL, Cutolo LRA. Contribuições para a discussão sobre a formação do odontológo a partir da inserção da saúde bucal na Estratégia Saúde da Família. ACM arq catarin med 2007; 36(4):76-83.

Artigo apresentado em 13/09/2009

Aprovado em 06/01/2010

Versão final apresentada em 25/01/2010 